\title{
Cell surface engineering with polyelectrolyte-stabilized magnetic nanoparticles: A facile approach for fabrication of artificial multicellular tissue-mimicking clusters
}

\author{
Maria R. Dzamukova ${ }^{\S}$, Ekaterina A. Naumenko ${ }^{\S}$, Elvira V. Rozhina, Alexander A. Trifonov, and \\ Rawil F. Fakhrullin ( $\square)$ \\ Bionanotechnology Lab, Institute of Fundamental Medicine and Biology, Kazan Federal University, Kreml uramı 18, Kazan, 420008, \\ Republic of Tatarstan, Russian Federation \\ $\S$ Both authors contributed equally to this study.
}

Received: 12 January 2015

Revised: 25 February 2015

Accepted: 2 March 2015

(C) Tsinghua University Press and Springer-Verlag Berlin Heidelberg 2015

\section{KEYWORDS}

magnetic nanoparticles, artificial multicellular clusters, magnetic modification

\begin{abstract}
Regenerative medicine requires new ways to assemble and manipulate cells for fabrication of tissue-like constructs. Here we report a novel approach for cell surface engineering of human cells using polymer-stabilized magnetic nanoparticles (MNPs). Cationic polyelectrolyte-coated MNPs are directly deposited onto cellular membranes, producing a mesoporous semi-permeable layer and rendering cells magnetically responsive. Deposition of MNPs can be completed within minutes, under cell-friendly conditions (room temperature and physiologic media). Microscopy (TEM, SEM, AFM, and enhanced dark-field imaging) revealed the intercalation of nanoparticles into the cellular microvilli network. A detailed viability investigation was performed and suggested that MNPs do not inhibit membrane integrity, enzymatic activity, adhesion, proliferation, or cytoskeleton formation, and do not induce apoptosis in either cancer or primary cells. Finally, magnetically functionalized cells were employed to fabricate viable layered planar (two-cell layers) cell sheets and 3D multicellular spheroids.
\end{abstract}

\section{Introduction}

Magnetically driven assembly of human cells into artificial multicellular clusters mimicking human tissues is regarded as a powerful tool in regenerative medicine $[1,2]$.

Magnetically facilitated tissue engineering employs the introduction of magnetic nanoparticles (MNPs) into or onto live cells as an effective means for remote magnetic field-based control of spatial deposition of cells and fabrication of layered tissue-like structures [3]. Over the past decade, researchers worldwide have focused on the elaboration of novel techniques for the effective magnetic functionalization of mammalian cells and their subsequent use for controllable cell assembly. Several reports demonstrate the successful

Address correspondence to kazanbio@gmail.com 
implementation of MNPs-modified cells in fabrication of artificial constructs imitating vascular tissue [4], skeletal muscle tissues [5], and keratinocyte sheets [6]. Magnetic functionalization of cells was also employed in fabrication of cellular spheroids [7], which are regarded as three-dimensional building blocks in tissue engineering and a prospective tool in pharmaceutical applications (i.e., drug screening) [8] and tumor studies [9]. MNPs-modified cells were also employed for fabrication of aortic valve mimics using a magnetic levitation procedure [10]. Overall, artificial addition of magnetic functionality in cells allows for effective spatial manipulation using relatively simple and accessible magnetic fields, which dramatically improves control over geometry, size distribution, and cell distribution within multicellular constructs, highlighting magnetic methods in tissue engineering as a promising direction in modern regenerative medicine.

Rendering cells with magnetic functionality requires labeling human cells with MNPs. To date, most published techniques have employed passive internalization of MNPs via endocytosis, which allows for effective magnetic modification of cells [11-13]. However, uptake of MNPs by cells entails several major drawbacks, such as (1) a lengthy internalization process, requiring up to $72 \mathrm{~h}$ of co-incubation of MNPs with cells [14, 15] and (2) potential toxic effects of early-stage cytoplasminternalized nanoparticles [16]. Early reports demonstrate the use of magnetic cationic liposomes (MCLs) fabricated using mixtures of 10-nm magnetite nanoparticles and lipids [5]. Use of positively charged MCLs as delivery vehicles improves the accumulation of MNPs in target cells via electrostatic interactions with negatively charged cellular membranes [4]. Magnetic nanoparticles are internalized into the cytoplasm via co-incubation of MCLs with cells for several hours. However, experimental approaches based on cell-internalized magnetic nanoparticles have raised concerns regarding possible long-term toxic effects. To minimize the potential toxic effects of MNPs, several recent studies have suggested using MNPs isolated from magnetotactic bacteria [17], which are believed to be less toxic than chemically synthesized MNPs, fabrication of magnetoferritin nanoparticles, or construction of Janus magnetic cellular spheroids by concentrating nanoparticles in certain regions of spheroids, thus reducing MNPs-cell interactions [8]. Although effective, these approaches are rather complex and require time-consuming manipulation of cells or sophisticated methods of nanoparticle preparation.

To avoid these obstacles, we recently suggested an alternative approach based on the deposition of poly(allylamine)-stabilized (PAH) MNPs on cell membranes [18]. Polymer-stabilized cationic magnetic nanoparticles self-assembled on cell membranes within several minutes and did not penetrate the cytoplasm of HeLa cells. Polyelectrolyte-stabilized MNPs readily assemble on cells, without use of any supramolecular linkers, such as streptavidin-biotin chemistry [19]. Subsequently, we employed PAH-MNPs-modified human cells for magnetically facilitated fabrication of lung tissue-mimicking multicellular clusters [20]. In this paper, we report the detailed study of cell surface engineering of human cells with polyelectrolytestabilized MNPs and demonstrate the magnetically facilitated fabrication of artificial multicellular clusters using MNPs-functionalized cells. We found that PAHMNPs-functionalization of cells does not affect the viability of cells, and that surface-engineered magnetic cells remain metabolically active, colonize available substrates, and gradually remove the nanoparticles from their surfaces. We investigated the distribution of MNPs on cell surfaces at early and late stages of cell growth. Cell surface engineering with PAH-MNPs allowed us to fabricate layered tissue-like clusters and multicellular spheroids, demonstrating the potential of our approach for tissue engineering.

\section{Experimental}

\subsection{Chemicals and materials}

All chemicals used in this study were purchased from Sigma-Aldrich unless otherwise noted, were of analytical grade, and were used as received. Ultrapure Milli-Q water was used throughout.

\subsection{Synthesis and characterization of MNPs}

MNPs were prepared as follows: $2.0 \mathrm{~mL}$ of $1 \mathrm{M} \mathrm{FeCl}_{3}$ and $0.5 \mathrm{~mL}$ of $2 \mathrm{M} \mathrm{FeCl}_{2}$ aqueous solutions were mixed and stirred vigorously, then $50 \mathrm{~mL}$ of $0.5 \mathrm{M}$ aqueous $\mathrm{NaOH}$ was added dropwise while stirring. The dark 
iron oxide precipitate was then separated using a magnet and washed extensively with water until the $\mathrm{pH}$ was neutral. To stabilize the MNPs with cationic PAH polymer, $1 \mathrm{~mL}$ of as-prepared nanoparticles was mixed with $10 \mathrm{~mL}$ of $10 \mathrm{mg} \cdot \mathrm{mL}^{-1}$ aqueous $\mathrm{PAH}$, and the mixture was sonicated for $10 \mathrm{~min}$, incubated for $12 \mathrm{~h}$, and then separated by centrifugation and washed with Milli-Q water. The hydrodynamic size and iron oxide core size of MNPs were determined using dynamic light scattering and atomic force microscopy (AFM).

\subsection{Cell lines and cultivation}

Primary human skin fibroblasts (HSF) were isolated from an adult skin biopsy sample and cultivated in minimal Eagle's medium Alfa $(\alpha$ MEM) supplemented with $0.2 \mathrm{mM}$ L-glutamine, $100 \mathrm{U} / \mathrm{ml}$ penicillin, $100 \mu \mathrm{g} / \mathrm{ml}$ streptomycin, and $10 \%$ heat-inactivated bovine serum (PAA Laboratories). Fibroblasts between the fourth and eleventh passages were used in the experiments. Human lung carcinoma epithelial cells (A549) were obtained from the American Type Culture Collection (ATCC, Rockville, Maryland, USA). A549 cells were cultivated in Dulbecco's modified minimal Eagle's medium (DMEM) with L-glutamine supplemented with $100 \mathrm{U} / \mathrm{ml}$ penicillin, $100 \mu \mathrm{g} / \mathrm{ml}$ streptomycin, and $10 \%$ fetal bovine serum (PAA Laboratories). Cells were routinely passaged after they approached $90 \%-95 \%$ confluence with $0.05 \%$ trypsin-EDTA solution (Gibco) and split at a ratio 1:10-1:20. For magnetization experiments, cells at $70 \%-90 \%$ confluence were split into a flask $\left(75 \mathrm{~cm}^{2}\right)$ at a ratio of 1:3 the day before use. Cells were detached from the surface of the flask using $0.05 \%$ trypsin-EDTA during $5 \mathrm{~min}$ of incubation followed by centrifugation and washing with DPBS.

\subsection{Functionalization of cells with MNPs}

A suspension of MNPs $(0.05 \mathrm{mg} / \mathrm{ml})$ in $0.15 \mathrm{M} \mathrm{NaCl}$ was filtered through a $0.22-\mu \mathrm{m}$ Millipore syringe filter to eliminate larger aggregates and to sterilize the suspension. The nanoparticle suspension was added to a $10^{6}$-cell pellet in a tube from which the supernatant had previously been removed. After 3 min of incubation with gentle vortexing, the cells were separated from the remaining MNPs by centrifugation $(1,000 \mathrm{rpm})$ and washed twice with DPBS.

\subsection{Physiological activity tests}

\subsubsection{Apoptosis induction}

The ability of MNPs to induce apoptosis was tested with ethidium bromide/acridin orange staining according to the manufacturer's protocol. Fluorescence microscopy was used to estimate cell viability in the stained samples. The enzymatic activity and percentage of apoptotic cells were evaluated using flow cytometry with Merocyanin 540 (MC540)/fluorescein diacetate (FDA) staining after 0,12 , and $24 \mathrm{~h}$ of incubation with MNPs. A BD FACSCanto (Biosciences) instrument was used. Data were obtained using the FACSDiva software.

\subsubsection{MTT assay}

The cytotoxicity of PAH-MNPs was determined using an 3(4,5-dimethylthiazoyl-2-yl) 2,5 diphenyltetrazolium bromide (MTT) assay. MTT is reduced by mitochondrial dehydrogenase in viable cells, producing insoluble purple formazan. MNPs-functionalized and intact A549 and HSF cells were plated in 96-well plates (7,000 cells per well) and allowed to attach overnight in a humidified atmosphere with $5 \% \mathrm{CO}_{2}$ at $37{ }^{\circ} \mathrm{C}$. The MTT stock solution $(5 \mathrm{mg} / \mathrm{ml})$ was prepared fresh in PBS from MTT powder, and $10 \mu \mathrm{l}$ of this solution was added to each $100 \mu \mathrm{l}$ of medium using a multichannel pipette; plates were incubated at $37^{\circ} \mathrm{C}$ for $4 \mathrm{~h}$. The medium was removed by inverting the plate on blotting tissue, and $200 \mu \mathrm{l}$ of dimethylsufoxide (DMSO) was added to each well to solubilize the formazan. The absorbance was measured using a microplate reader (Multiskan FC, Thermo Fisher Scientific, USA) at $540 \mathrm{~nm}$.

\subsubsection{Neutral red uptake assay}

The neutral red (NR) working solution $(0.033 \%)$ was prepared in appropriate culture medium immediately prior to performing the test and filtered through a $0.22-\mu \mathrm{m}$ syringe filter. MNPs-functionalized and intact A549 and HSF cells were plated into 96-well culture plates $(10,000$ cells per well) and incubated in a humidified atmosphere with $5 \% \mathrm{CO}_{2}$ at $37^{\circ} \mathrm{C}$ for $24 \mathrm{~h}$. The medium was replaced with $200 \mu \mathrm{L}$ of NR working solution, and plates were incubated in a $\mathrm{CO}_{2}$-incubator for $3 \mathrm{~h}$. Next, the cells were fixated with $10 \%$ formaldehyde and $10 \% \mathrm{CaCl}_{2}$ for $1 \mathrm{~min}$ at room temperature. 
The dye was extracted from cells using $200 \mu \mathrm{L}$ of solvent solution ( $1 \%$ glacial acetic acid in $50 \%$ ethanol, prepared immediately before use). The optical density of the NR solution was measured at $540 \mathrm{~nm}$ and $690 \mathrm{~nm}$ (reference value) using a microplate reader after shaking for $15 \mathrm{~min}$ at room temperature.

\subsubsection{Resazurin reduction assay}

MNPs-functionalized and intact A549 and HSF cells were seeded in 96-well plates (7,000 cells per well) and cultivated in a humidified atmosphere with $5 \% \mathrm{CO}_{2}$ at $37^{\circ} \mathrm{C}$ for $24 \mathrm{~h}$. The culture medium was removed and replaced with $200 \mu \mathrm{l}$ of resazurin solution $\left(0.01 \mathrm{mg} \cdot \mathrm{ml}^{-1}\right)$ in an appropriate culture medium, and plates were incubated overnight. The absorbance was measured at $570 \mathrm{~nm}$ using a microplate reader. The rate of resazurin reduction is directly proportional to the number of viable cells.

\subsubsection{Acridine orange and ethidium bromide staining}

Acridine orange/ethidium bromide ( $\mathrm{AO} / \mathrm{EtBr})$ staining combined with fluorescent microscopy was used to distinguish early apoptotic from necrotic cells. AO intercalates into DNA, producing green fluorescence, and the nuclei of viable cells appear green. Early apoptotic cells show condensed or fragmented green nuclei. EtBr can be taken up only by non-viable cells with damaged membranes; dead cells show a bright orange nucleus. MNPs-functionalized and intact A549 and HSF cells were plated into 96-well plates (10,000 cells per well) and incubated in a humidified atmosphere with $5 \% \mathrm{CO}_{2}$ at $37^{\circ} \mathrm{C}$ for $24 \mathrm{~h}$. Then cells were stained with $10 \mu \mathrm{l}$ of $\mathrm{AO} / \mathrm{EtBr}$ solution $(1 \%$ and $0.5 \%$, respectively) for $5 \mathrm{~min}$ and visualized using a fluorescence microscope to estimate the number of apoptotic, necrotic, and viable cells.

\subsection{Scaffold-free tissue engineering using magnetic cells}

\subsubsection{Layered multicellular clusters}

We employed $\mathrm{NdFeB}$ cylindrical rod-shaped magnets (E-magnets, UK) that were $3 \mathrm{~mm}$ in diameter, $4 \mathrm{~mm}$ long, with a pull strength of $0.27 \mathrm{~kg}$.

First layer: MNPs-coated HSF cells (3,000 cells per well) were seeded in 6-well culture plates, then $3 \mathrm{~mm}$
NdFeB cylindrical magnets were deposited below each culture well. The cells were incubated for $24 \mathrm{~h}$, and then the wells were flushed with DPBS to remove non-attached cells.

Second layer: The procedure was repeated using MNPs-coated A549 cells (5,000 cells per well). After incubating the cells for $24 \mathrm{~h}$, the round multicellular clusters were collected using a permanent magnet or a pipette tip and further characterized.

\subsubsection{Fabrication of magnetic spheroids (culture of one cell type)}

A549 cells were coated with PAH-MNPs, as described above. For spheroid formation, $15-\mu 1$ drops of culture medium containing 2,000 magnetically functionalized cells were placed on the inner side of a culture dish. Then the cap was inverted and the culture dish was covered with $1.5 \mathrm{ml}$ of DPBS. Cells were cultured in hanging drops in a humidified atmosphere with $5 \%$ $\mathrm{CO}_{2}$ at $37^{\circ} \mathrm{C}$.

\subsubsection{Fabrication of hybrid magnetic spheroids (culture of} two cell types)

Hybrid multicellular spheroids were formed using two types of magnetically functionalized cells (A549 and HeLa cells) by mixing cell suspensions ( $\sim 500$ cells of each type for 1 spheroid). Cells of both cell types were fluorescently tagged using dialkylcarbocyanines (Vibrant ${ }^{\circledR}$, Invitrogen): DID (fluorescence excitation (Ex) and emission (Em) maxima at $644 \mathrm{~nm}$ and $665 \mathrm{~nm}$, respectively) was used for labeling of A549 cells; HeLa cells were labeled using Dil (fluorescence Ex and Em maxima at $549 \mathrm{~nm}$ and $565 \mathrm{~nm}$, respectively). After fabrication, samples were imaged using confocal microscopy.

\subsubsection{F-actin staining and imaging}

Spheroids grown on sterile coverslips were washed twice with PBS. Then the spheroids were fixated using 4\% paraformaldehyde in PBS for $10 \mathrm{~min}$, followed by washing in PBS. Cells were permeabilized with $1 \%$ Triton X-100 in PBS for 3-5 min followed by washing in PBS. Then blocking solution (1\% BSA in PBS) was applied for $30 \mathrm{~min}$ to prevent nonspecific binding. One unit of Alexa Fluor $488{ }^{\circledR}$ phalloidin conjugate (Life Technologies) in $200 \mu \mathrm{l}$ was applied to each 
sample followed by washing twice in PBS. Then the coverslips were dried and embedded into Eukitt mounting media. Samples were examined using confocal microscopy.

\subsection{Characterization techniques}

Hydrodynamic diameters and $\zeta$-potentials of nanoparticles and cells were measured using a Malvern Zetasizer Nano ZS instrument. Optical and fluorescence microscopy images were obtained using a Carl Zeiss Axio Imager microscope equipped with an AxioCam HRC CCD camera. Cell culture wells were examined using a Zeiss Observer Z1 inverted microscope. TEM images of the thin-sectioned MNPs-functionalized cells were obtained using a JEOL 1200 EX microscope operating at $80 \mathrm{kV}$. The cells were fixed with $2.5 \%$ glutaraldehyde, gradually dehydrated using ethanol, embedded into EPON resin, and then thin sections were cut using an LKB ultramicrotome equipped with a diamond knife and mounted on copper grids. The samples were stained with $2 \%$ aqueous uranyl acetate and lead citrate. SEM images were obtained using a Merlin Carl Zeiss instrument. Cells were dehydrated and placed on SEM stubs. Samples were sputter-coated with $\mathrm{Au}(60 \%)$ and $\mathrm{Pd}(40 \%)$ alloy using a Q150R (Quorum Technologies) instrument. Images were obtained at $3 \times 10^{-4} \mathrm{~Pa}$ working pressure and $15 \mathrm{kV}$ accelerating voltage using the InLens detection mode. AFM images of MNPs and MNPscoated cells were obtained using a Dimension FastScan instrument (Bruker) with ScanAsyst-Air probes working at a scan rate of $1.7 \mathrm{~Hz}$. The images were processed using NanoScope Analysis software (Bruker). Confocal microscopy images were collected using a Carl Zeiss LSM 780 microscope, and images were processed using ZEN software.

\section{Results and discussion}

\subsection{Magnetic nanoparticle synthesis and characterization}

Functionalization of human cells with magnetic nanoparticles for tissue engineering requires the use of highly biocompatible nanoparticles, since toxic effects may severely damage the cells. We synthesized
PAH-coated iron oxide nanoparticles, which have previously been applied for magnetic functionalization of microbes [21-23] and human cells [18, 20]. The deposition of nanoparticles onto cells is based on the relatively short ( $\sim \mathrm{min})$ exposure of cells to PAHMNPs dispersed in the appropriate isotonic saline media. Surface functionalization of human cells imposes several important limitations on the design of nanoparticles: (1) MNPs should be stable in physiological buffers of relatively high salinity, and (2) MNPs must be sterilized prior to deposition onto cells. Importantly, nanoparticles should not penetrate into nanocoated cells at early stages of functionalization; in other words, the nanocoatings should be localized exclusively on the outer surfaces of the cellular membranes. The uniformity and size distribution of PAH-stabilized MNPs was characterized using AFM, and a typical AFM image of MNPs is shown in Fig. 1(a). Individual nanoparticles in pure water were found to be approximately $29 \pm 5 \mathrm{~nm}$ in size, which corresponds well with our previous results [24]. Nanoparticles form well-dispersed aggregates, which can be visualized using enhanced dark field (EDF) microscopy (Fig. 1(b)). Imaging of PAH-MNPs using EDF microscopy is an important tool for investigating the distribution of PAH-MNPs on cellular membranes, and it facilitates the detection of nanoparticles in situ, without pre-treatment or fixation of cells.

Normally, hydrophilic nanoparticles tend to aggregate if dispersed in physiological saline solutions [20]. Aggregated nanoparticles (with sizes exceeding $200 \mathrm{~nm}$ ) cannot be effectively filtered through $220-\mathrm{nm}$ pore filters, thus severely limiting the application of MNPs in human cell functionalization. We investigated the aggregation of PAH-MNPs in saline buffers by automatic titration of nanoparticle suspensions and found that PAH-coated nanoparticles were stable within the physiological range of salinity, retaining their hydrodynamic diameters $(\sim 180 \mathrm{~nm})$ and positive zeta-potential $(+20 \mathrm{mV})$, as shown in Fig. 1(c). Nanoparticles aggregated (and showed drastically reduced zeta-potentials) only at $0.5 \mathrm{M} \mathrm{NaCl}$, which is far above the level necessary for biocompatibility $(0.15 \mathrm{M})$. The relatively small size of the aggregated MNPs allowed successful filtration of the MNPs suspensions using $0.22-\mu \mathrm{m}$ filters to maintain sterility, while the positive 


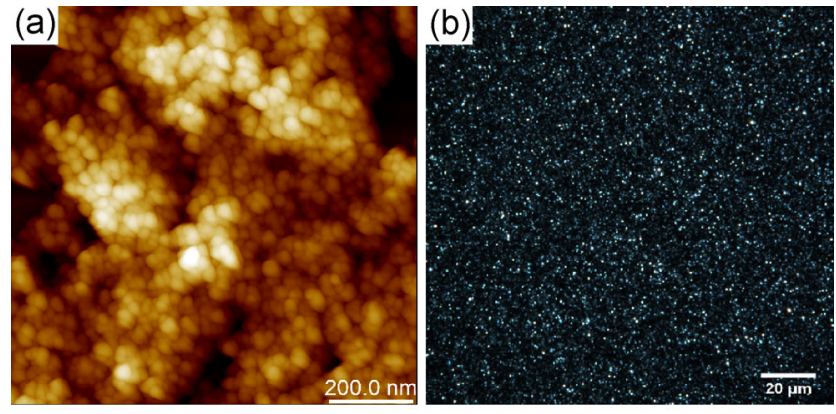

(c)

PAH-stab. MNP

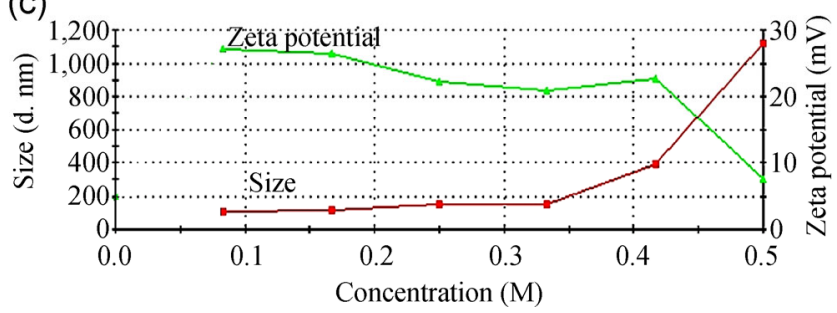

Figure 1 Characterization of PAH-stabilized MNPs. (a) AFM image of PAH-stabilized MNPs; (b) enhanced dark-field optical microscopy image of PAH-stabilized MNPs; (c) the stability of PAH-stabilized MNPs in increasing $\mathrm{NaCl}$ concentrations, as determined using simultaneous hydrodynamic diameter and zetapotential measurements.

zeta-potential of the MNPs promoted their selfassembly on the cellular membranes.

\subsection{Human cell surface engineering with PAH- stabilized MNPs}

In this study, we used two types of isolated human cells (adenocarcinomic human alveolar basal epithelial cells, or A549 cells, and primary skin fibroblasts (HSF)) for magnetic surface functionalization with PAHstabilized MNPs. The magnetization procedure is rapid and is based on introduction and brief incubation ( $\sim 5 \mathrm{~min})$ of suspended cells into a suspension of MNPs ( $0.05 \mathrm{mg}$ MNPs per $10^{6}$ cells). An excess volume of MNPs was used to ensure the homogenous and uniform deposition of MNPs onto cellular membranes. Aggregated, positively charged MNPs readily assemble on negatively charged human cells, but the overall negative charge of cells remains unchanged (Table 1).

This suggests that magnetic nanoparticles deposited at the selected relatively low concentration do not completely cover the cells, as shown in our previous study of HeLa cells (at higher concentrations of MNPs) [18]; instead, they form a rather thin and scattered mesoporous coating. To characterize MNPs deposition
Table 1 Zeta-potential measurements of A549 and HSF cells before and after cell surface engineering with PAH-MNPs

\begin{tabular}{ccc}
\hline Cells & Zeta-potential (intact) & $\begin{array}{c}\text { Zeta-potential } \\
\text { (MNPs-coated) }\end{array}$ \\
\hline A549 & $-24.5 \pm 0.5 \mathrm{mV}$ & $-23.8 \pm 0.7 \mathrm{mV}$ \\
HSF & $-20 \pm 0.6 \mathrm{mV}$ & $-19 \pm 0.9 \mathrm{mV}$ \\
\hline
\end{tabular}

on cells, we applied optical, scanning electron (SEM), transmission electron (TEM), and hyperspectral microscopy $(\mathrm{HM})$. As previously demonstrated on microbial [23, 24] and human cells [18, 20, 25], the layers of PAH-stabilized MNPs on cellular membranes can clearly be visualized under an optical microscope using the bright field imaging mode. Figures 2(a)-2(d) shows optical microscopy images of surface-modified MNPs-coated A549 and HSF cells, along with their uncoated counterparts. The morphology of the magnetically functionalized cells was not affected by the MNPs aggregates, which were arranged into a relatively thick mesoporous monolayer on the cell membranes. SEM images of MNPs-coated cells (Figs. 2(e)-2(h)) also confirmed the uniform deposition of MNPs, which apparently intercalate and preferentially attach to the negatively charged carbohydrate-rich microvilli network. Although the density of nanoparticles was relatively high, free microvilli can still be clearly seen in the SEM images. Moreover, SEM imaging requires drying and sputter-coating of cells with a thin conductive layer, inducing closer contact between MNPs and microvilli, whereas in native environments the microvilli usually protrude through the monolayer of MNPs. This was further confirmed using TEM of thin-cut resin-embedded cells (Figs. 2(i)-2(1)), demonstrating the exclusive localization of MNPs on the outer surfaces of cellular membranes, where they were attached to the microvilli. The extracellular localization of PAH-stabilized MNPs increases the biocompatibility of this facile magnetization approach, compared with conventional magnetization approaches based on intracellular labeling [26]. Importantly, the mesoporous MNPs-nanoshells are permeable to nutrients and other macromolecules, which would facilitate cell growth and proliferation. The nanoparticle layer completely encircles the cells, and thus can also be utilized to attenuate the adhesive properties of MNPs-coated cells. 

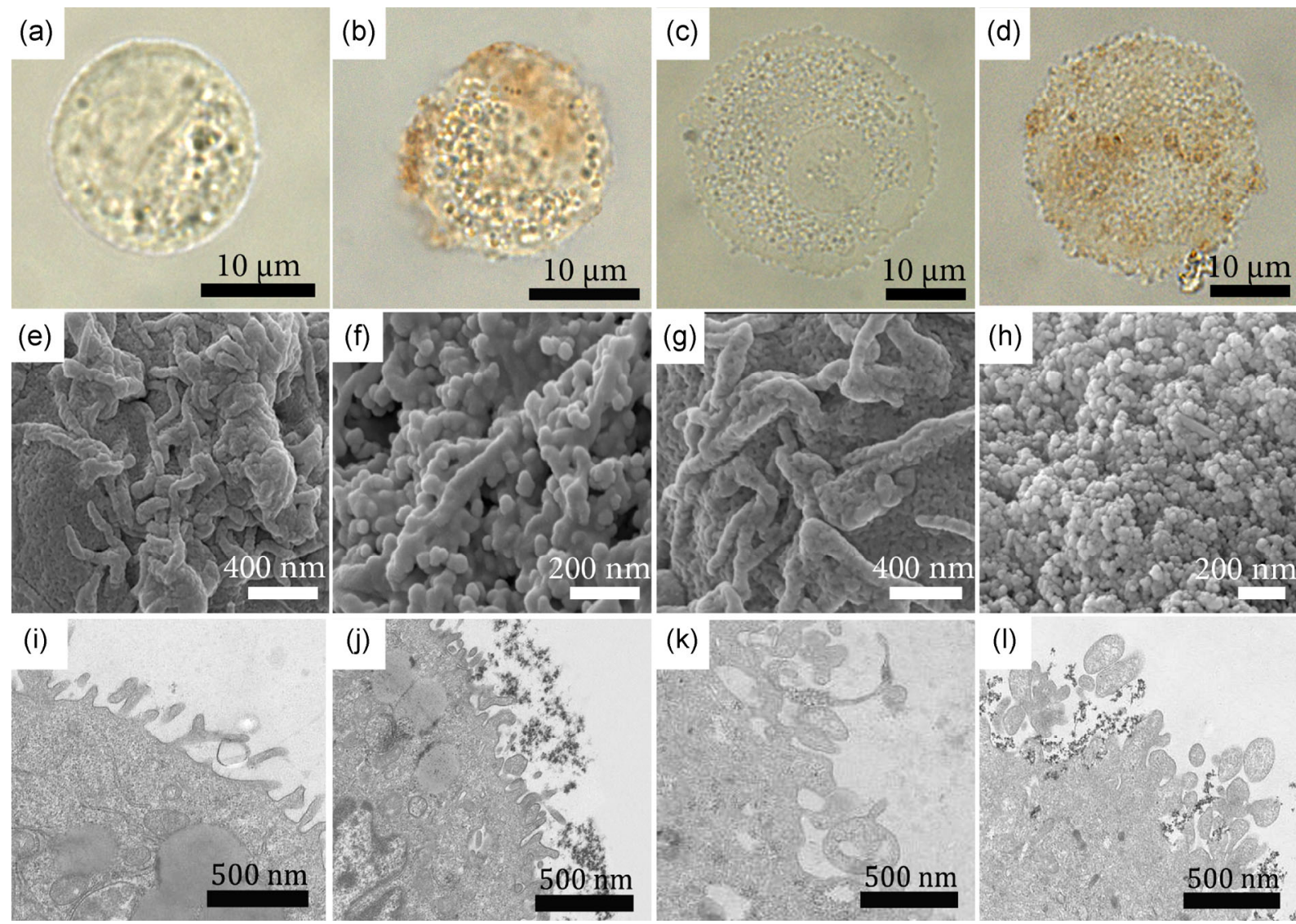

Figure 2 Bright-field optical microscopy images of intact A549 (a) and HSF (c) cells and MNPs-coated A549 (b) and HSF (d) cells (note the characteristic brown color of the cells caused by MNPs deposition); SEM images of intact A549 (e) and HSF (g) cells and MNPs-coated A549 (f) and HSF (h) cells; TEM images of intact A549 (i) and HSF (k) cells and MNPs-coated A549 (j) and HSF (l) cells.

Additionally, we investigated PAH-stabilized MNPscoated cells using hyperspectral microscopy (Fig. 3). The reflected light spectral response depends on the optical properties of the intact and PAH-stabilized MNPs-coated cells; magnetized cells are outlined by the relatively thick layer of MNPs. A characteristic peak at $420 \mathrm{~nm}$ was observed for MNPs-coated cells, whereas the intact cells did not exhibit clear peaks within 420-820 nm. True-color rendered hyperspectral images of intact and MNPs-coated HSF cells are shown in the insets in Fig. 3; the characteristic brown hue of MNPs can clearly be seen on the MNPs-coated cells. Similar results were obtained for A549 cells (data not shown).

Intensity-normalized reflected light spectra profiles of MNPs-coated cells and intact cells can be applied for differentiation of MNPs-coated cells in cell mixtures. Using hyperspectral mapping (data not shown), we determined that $100 \%$ of both A549 and HSF cells were coated with MNPs, if coated using the predetermined low-concentration $\left(0.05 \mathrm{mg}\right.$ per $10^{6}$ cells) MNPs suspension in saline buffer. We previously demonstrated that higher concentrations of MNPs can also be applied [18]; however, we believe that the delicate procedure of artificial tissue assembly requires application of the lowest effective concentration of MNPs for functionalization of cells.

\subsection{PAH-stabilized MNPs do not affect the physiological properties of magnetized human cells}

Although the magnetic modification of human cells has become a routine method in tissue engineering research $[1,2,10]$, limited data are currently available on the effects of MNPs on magnetically modified cells. Particularly, magnetization approaches based on intracellular introduction of MNPs into the cytoplasm 


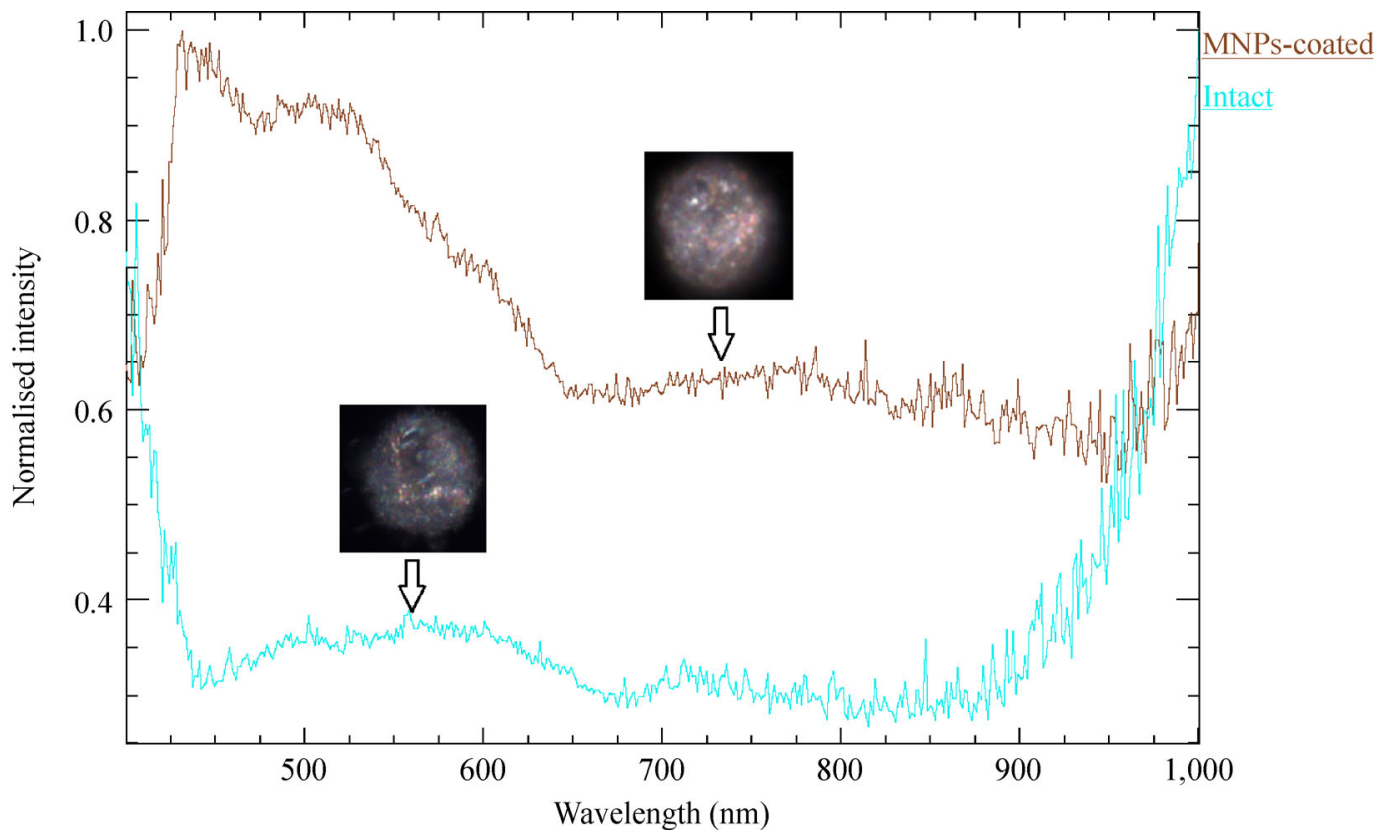

Figure 3 Reflected light spectra obtained from MNPs-coated and intact HSF cells (typical hyperspectral images of cells are given in insets).

were used to systematically assess the influence of MNPs on cellular physiology, although to date only limited data has been published, based on either viability dyes tests $[27,28]$ or enzyme activity tests [29]. In this study, we thoroughly investigated the physiological activity of PAH-stabilized MNPs-coated A549 and HSF cells, employing a complex approach based on the simultaneous investigation of membrane integrity, enzyme activity, and apoptosis induction in magnetically modified cells. First, we applied viability staining using an ethidium bromide/acridine orange dye mixture, which allows viable cells to be distinguished from their dead counterparts. Magnetic nanoparticles attached to the cellular membranes can potentially damage membranes; therefore, it was important to demonstrate that membrane integrity is preserved in PAH-stabilized MNPs-coated human cells, as shown in Figs. 4(a)-4(d). Fluorescence microscopy images of intact and MNPs-coated A549 and HSF cells demonstrated that the magnetization procedure does not significantly reduce the integrity of cellular membranes in MNPs-coated cells.

Next, we investigated whether cell surface functionalization with MNPs induces apoptosis in magnetic human cells. We employed merocyanine 540 (MC540) dye, which adsorbs on the cellular membranes at the early stages of apoptosis, along with flow cytometry measurements at 12 and $24 \mathrm{~h}$ of incubation after magnetization. Fluorescein diacetate (FDA) viability dye was used to counterstain viable cells. The results are shown in Fig. 4(e) and in Table 2. Flow cytometry allowed us to simultaneously identify populations of cells stained with either dye. Overall, magnetic functionalization did not significantly increase the number of apoptotic cells in either cell line studied. Specifically, in the case of magnetically coated A549 cells, the largest number of cells observed constituted the FDA-positive/merocyanine540-negative (95.5\%) population, which are viable non-apoptotic cells, whereas the number of apoptotic cells was very low (3.1\%). Similar results were observed for MNPs-coated HSF cells. The higher levels of apoptotic HSF cells compared with the A549 cells are likely to have been caused by the physiological characteristics of cultured primary skin fibroblast cells. Notably, after $24 \mathrm{~h}$ of growth no apoptotic cells retained viability in either magnetized or intact A549 cells, whereas in HSF cells we observed a minor fraction ( $1 \%)$ of viable apoptotic cells. We also observed a significant increase in necrotic cells populations in both intact and magnetized human skin fibroblasts, compared with A549 cells. However, the absolute numbers of apoptotic and necrotic cells 

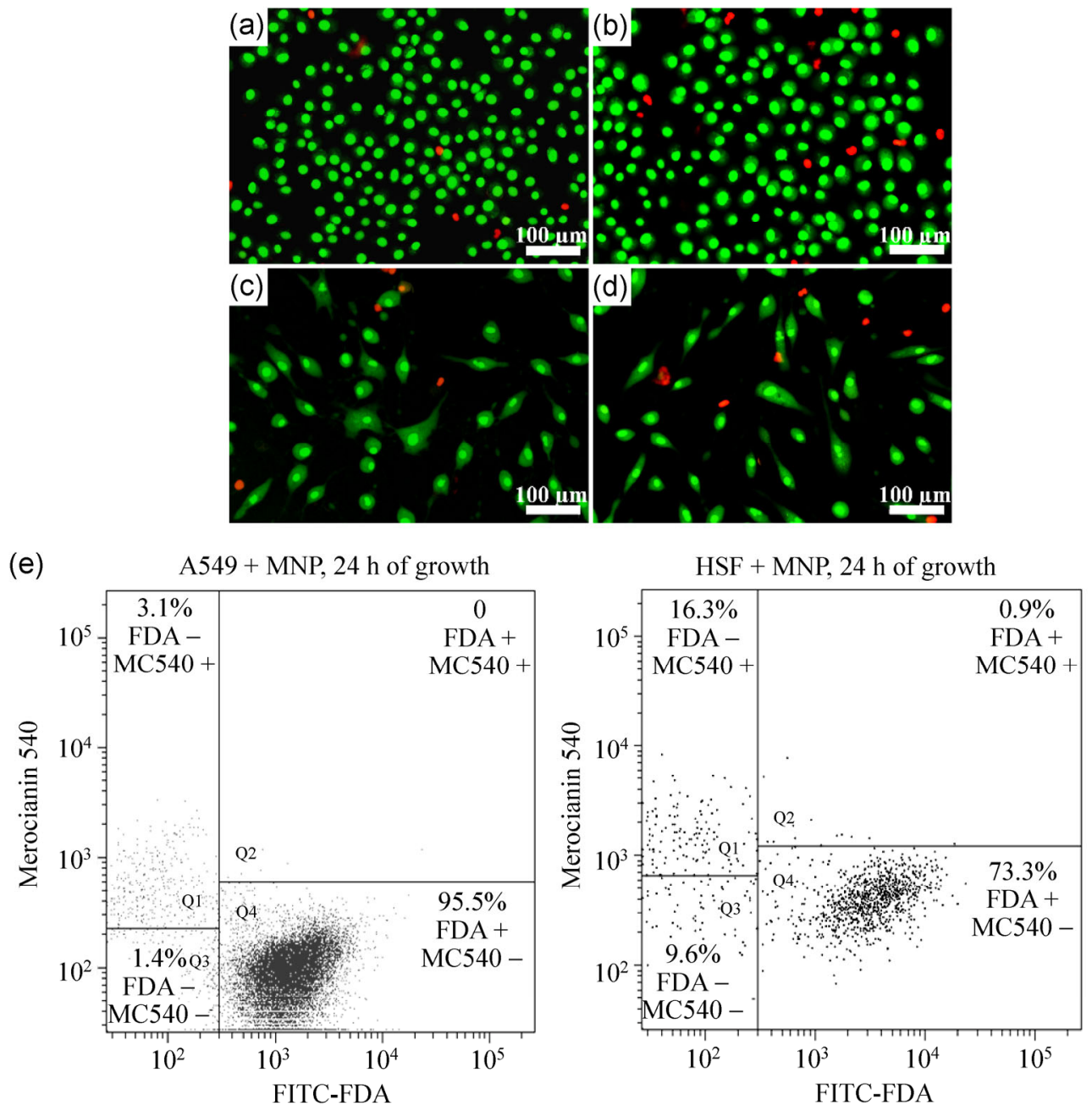

Figure 4 Fluorescence microscopy images of intact and MNPs-coated A 549 ((a), (c)) and HSF ((b), (d)) cells stained with ethidium bromide (red, nuclei of dead cells) and acridin orange (green, cytoplasm of live cells); flow cytometry data (e) demonstrating merocyanine 540 test for apotosis induction.

Table 2 Flow cytometry data demonstrating the viability of MNPs-functionalized A549 and HSF cells: simultaneous staining with FDA (viability) and merocianin (apoptosis) dyes. The data demonstrates the absence of an influence of magnetic functionalization on apoptosis induction in A549 cells and weak induction of apoptosis in HSF cells

\begin{tabular}{|c|c|c|c|c|c|c|}
\hline \multirow{2}{*}{$\frac{\text { Cells }}{\text { Time }}$} & \multicolumn{3}{|c|}{ A549 } & \multicolumn{3}{|c|}{ HSF } \\
\hline & $\begin{array}{l}\text { FDA-positive/ } \\
\text { MC540-negative } \\
\text { (control/with } \\
\text { MNPs) }\end{array}$ & $\begin{array}{l}\text { FDA-positive/ } \\
\text { MC540-negative } \\
\text { (control/with } \\
\text { MNPs) }\end{array}$ & $\begin{array}{l}\text { FDA-negative/ } \\
\text { MC540-positive } \\
\text { (control/with } \\
\text { MNPs) }\end{array}$ & $\begin{array}{l}\text { FDA-positive/ } \\
\text { MC540-negative } \\
\text { (control/with } \\
\text { MNPs) }\end{array}$ & $\begin{array}{l}\text { FDA-positive/ } \\
\text { MC540-negative } \\
\text { (control/with } \\
\text { MNPs) }\end{array}$ & $\begin{array}{c}\text { FDA-negative/ } \\
\text { MC540-positive } \\
\text { (control/with } \\
\text { MNPs) }\end{array}$ \\
\hline $0 \mathrm{~h}$ & $96 \% / 91.4 \%$ & $1.8 \% / 1 \%$ & $2.0 \% / 7 \%$ & $89.2 \% / 84.7 \%$ & $3.9 \% / 1.7 \%$ & $6.5 \% / 9.7 \%$ \\
\hline $12 \mathrm{~h}$ & $95.7 \% / 95.1 \%$ & $0.3 \% / 0.1 \%$ & $3.9 \% / 4.1 \%$ & $82.9 \% / 70.5 \%$ & $2.2 \% / 3.7 \%$ & $11 \% / 24.8 \%$ \\
\hline $24 \mathrm{~h}$ & $97.4 \% / 95.5 \%$ & $0 / 0$ & $2.1 \% / 3.1 \%$ & $75.1 \% / 71.3 \%$ & $1 \% / 0.65 \%$ & $21.9 \% / 22 \%$ \\
\hline
\end{tabular}


were very low, indicating that cell surface engineering with MNPs is a biocompatible approach, which we attribute to the exclusive localization of MNPs on outer cellular membranes, whereas the accumulation of MNPs in lysosomes leads to prominent toxic effects [30]. Our results clearly demonstrate that magnetic functionalization with PAH-stabilized MNPs did not induce apoptosis in cancerous cells (A549) and caused negligible induction of apoptosis in primary (HSF) cells.

To investigate the enzymatic activity of the MNPscoated A549 and HSF cells, we employed a set of colorimetric assays, namely the NR uptake test, MTT assay, and resazurin assay. These tests demonstrate the physiological activity of different enzymatic cellular ensembles, and were applied simultaneously to thoroughly examine the potential toxic effects of cell surface-attached MNPs. Overall, we conclude that the enzymatic activity of MNPs-coated cells was not affected, which indicates the high biocompatibility of cell surface functionalization with MNPs. During incubation with cells, resazurin is reduced by mitochondrial enzymes, producing the pink pigment resorufin. The results of the resazurin reduction test (Fig. 5(a)) confirmed that redox enzymatic activity was unaffected in MNPs-modified cells. NR is a cationic dye that penetrates the cell membrane and accumulates in lysosomes, where it binds with anionic sites of the lysosomal matrix [31]. The results of the NR test (Fig. 5(b)) demonstrate that the lysosomal activity of magnetically modified cells was unaffected. Based on the preserved functionality of three separate intracellular enzyme systems, we conclude that PAHstabilized MNPs do not inhibit the enzymatic activity of surface-magnetized cells. The results of the MTT assay (Fig. 5(c)) confirm the negligible influence of magnetic nanoparticles on the enzymatic activity of $\mathrm{NAD}(\mathrm{P}) \mathrm{H}$-dependent oxidoreductases. We assume that the intact membranes, enzyme activity, and low levels of apoptosis induction observed in MNPs-coated cells indicate that these cells will grow in a manner identical to intact A549 and HSF cells.

Finally, given the possible toxic effects of MNPs on the cytoskeleton, we investigated the distribution of F-actin in magnetically functionalized A549 cells using fluorescent-labeled Alexa Fluor $488^{\circledR}$ phalloidin conjugate and DAPI nuclear stain (Fig. 6). We detected no visible changes in F-actin distribution in PAHMNPs-coated cells compared with intact cells.

\subsection{Proliferation of PAH-MNPs-coated cells}

After confirming that the viability and physiologic activity of PAH-MNPs surface-engineered human cells were not compromised, we focused on investigation of the growth of the magnetized cells after attachment to a substrate. Both A549 and HSF cells were magnetized and cultivated normally, along with intact cells. PAH-MNPs-coated cells colonized the substrate (culture well bottoms) as well as intact cells; notably, distinct halo-like brown aggregates of magnetic nanoparticles could clearly be seen in optical microscopy images of the central areas of the cells [20], which is a characteristic feature of MNPs-modified cells. After examining representative optical microscopy images
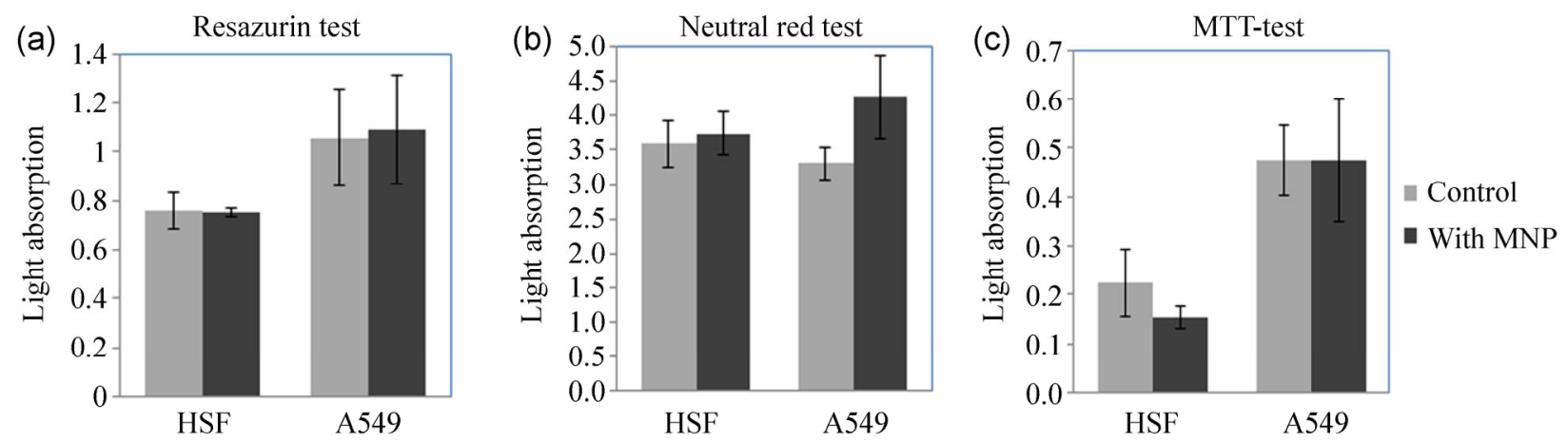

Figure 5 Quantitative analysis of enzymatic activity in MNPs-coated cells. MTT assay (c): magnetic functionalisation has a weak influence on the activity of mitochondrial dehydrogenases in HSF; Resazurin assay (a): MNPs do not affect mitochondrial enzymes in cells; Neutral red test (b): lysozomal activity is preserved in MNPs-coated cells. 
(data not shown), we found that the characteristic morphology of magnetically functionalized cells matched that of intact cells. Adhesion of cells to substrates is a complex process that occurs as a result of close cooperation of cell surface adhesion proteins and the cytoskeleton. Adhesion (Fig. 7(a)) starts when the initially round suspended cell attaches to the substrate, then cell spreading occurs, and finally specialized contacts between the cell and the substrate are established [32]. As long as surface-functionalization of cells with PAH-MNPs does not disrupt the activity of enzymes in the cytoplasm, we presume that magnetic nanoparticles deposited on cellular membranes do
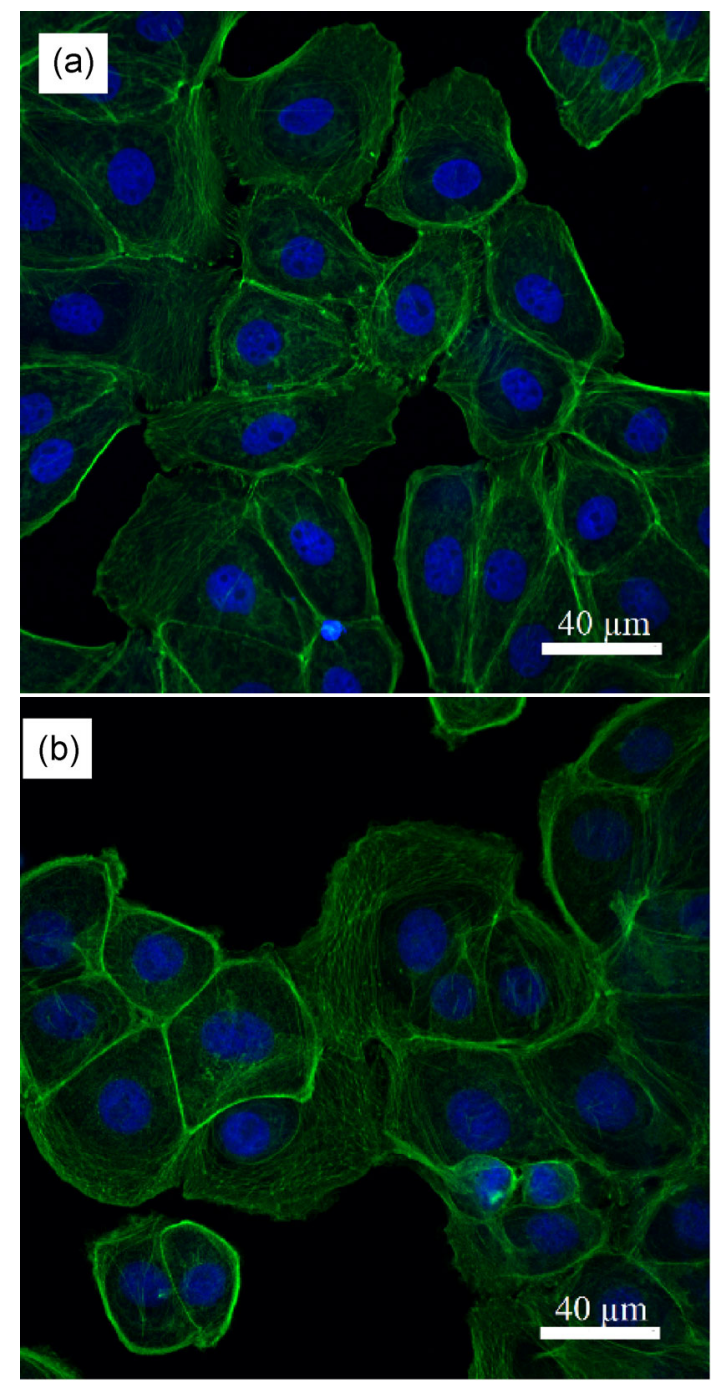

Figure 6 F-actin distribution in intact (a) and magnetically functionalized A549 cells (b); no differences in cytoskeleton organization were observed. Alexa Fluor 488 ${ }^{\circledR}$ phalloidin conjugate and DAPI nuclear stain were applied. not induce the inhibition of cytoskeleton dynamic activity (such as microtubule synthesis, etc.) as well. A more profound effect on cellular adhesion might be expected from the interaction of MNPs with cell surface adhesion proteins, which might be affected by the nanoparticles attached to the cell membranes. However, we found that the growth rates of MNPscoated cells were similar to, if not exceeding, those of intact cells [20]. As seen in high-resolution SEM and TEM images (Figs. 2(e)-2(l)), MNPs intercalate the cellular microvilli, but do not completely cover the cellular surface, thus allowing direct contact between the membrane and the substrate; as a result, cells are capable of attaching to and spreading on substrates in a normal manner.

Next, we investigated the distribution of PAH-MNPs on cellular membranes after adhesion and spreading of cells during $24 \mathrm{~h}$ of growth. We employed AFM to demonstrate that aggregated MNPs were located around cellular nuclei (Fig. 7). The nanoparticles were located precisely where the dense brown aggregates were detected using optical microscopy (Figs. 2(a)2(d)).

We also applied TEM imaging of thin-sectioned MNPs-coated cells after $24 \mathrm{~h}$ of growth to determine that MNPs are partially taken up by cells during proliferation (Figs.7(e) and 7(i)), suggesting that internalization may also contribute to the distribution of MNPs between proliferating cells. Growing and dividing cells are expected to gradually shed external surface coatings, as known from microbial cells [33]. Apart from highly visible aggregated MNPs localized on perinuclear areas, we expected to detect isolated nanoparticles on distal areas of cells. To investigate the distribution of nanoparticles on surface-attached cells, we applied dark field microscopy together with hyperspectral imaging. Figures $8(a)$ and $8(\mathrm{~b})$ show merged fluorescence (DAPI) and EDF (MNPs) images of magnetically functionalized A549 and HSF cells. One can see that nanoparticles (bright spots) are located not only around nuclei, but are also distributed on the cell membranes of distal parts of cells. This effect can be better visualized in the hyperspectral images (Figs. 8(c) and 8(d)).

We also applied hyperspectral mapping to distinguish aggregated nanoparticles from single nanoparticles, 
(a)

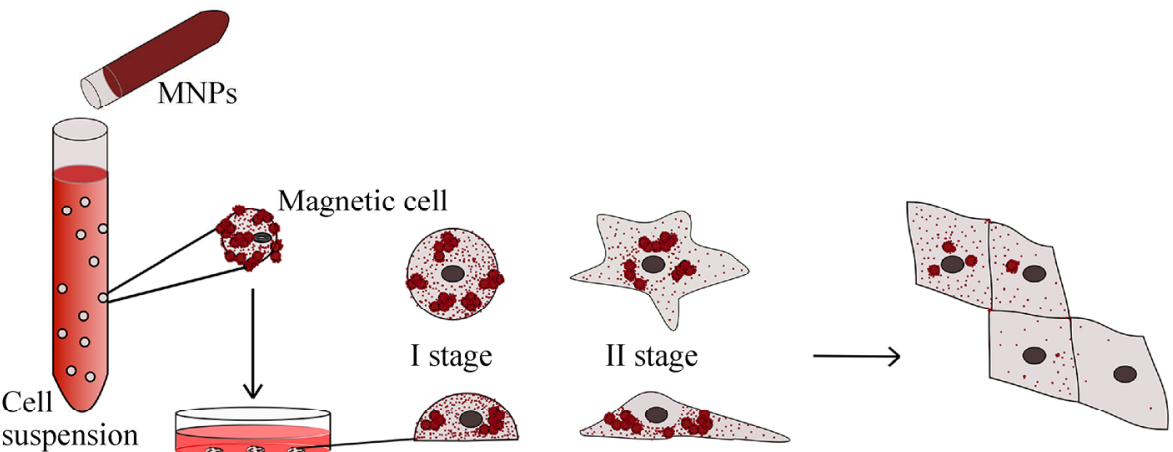

Attachment

Division
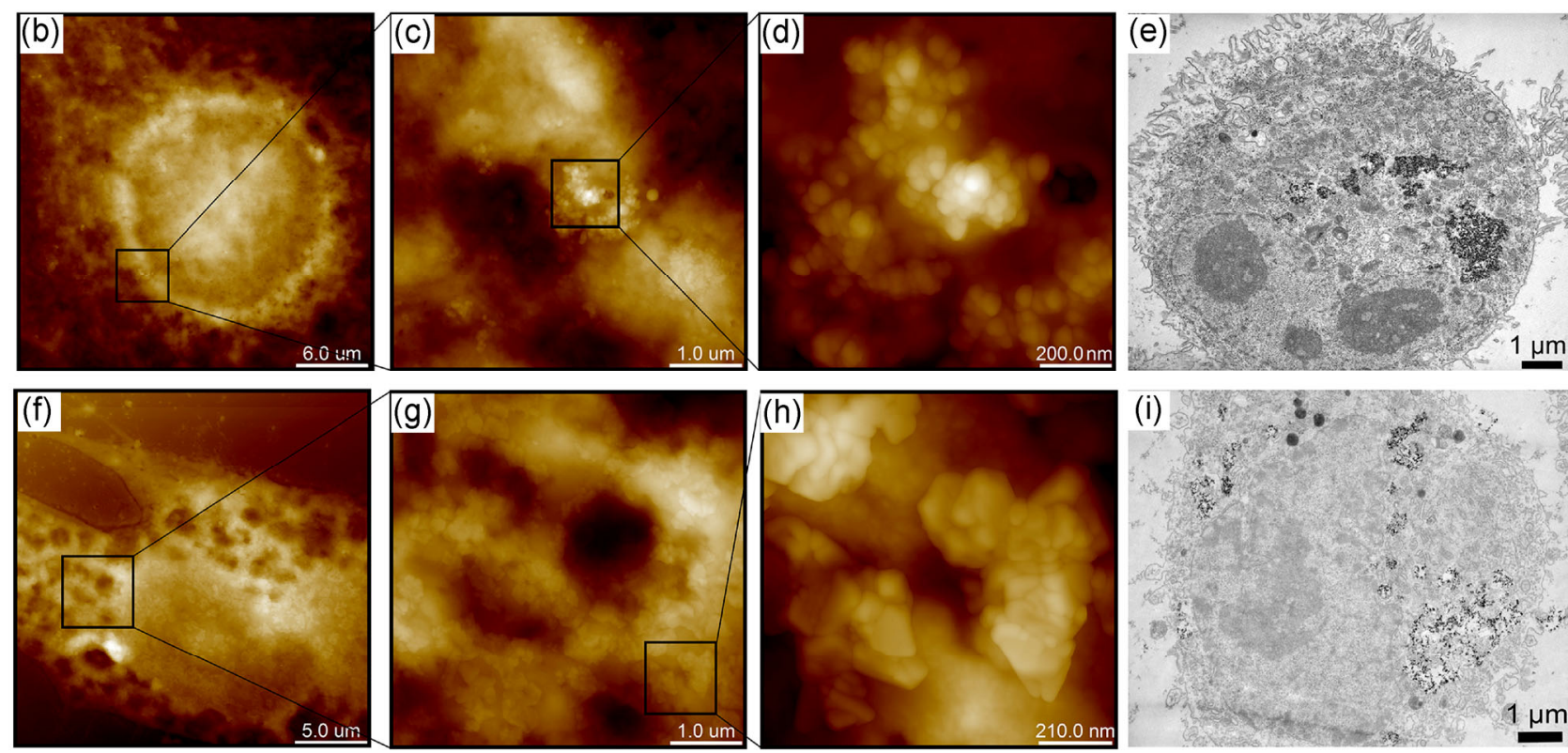

Figure 7 A sketch demonstrating the adhesion and proliferation of MNPs-coated human cells and MNPs cluster distribution between "mother" and "daughter" cells (a), AFM images (at increasing magnification) showing the aggregated PAH-MNPs on surface-attached A549 (b)-(d) and HSF (f)-(h) cells and TEM images demonstrating the internalisation of MNPs into growing A549 (e) and HSF (i) cells.

which exhibit different reflected light spectra. The results are given in Figs. 8(e) and 8(f); aggregated MNPs are shown in red, whereas single MNPs are shown as green dots (simulated colors). As seen in the images, some of the cells were coated with mostly non-aggregated MNPs, while others were densely coated with both aggregated and non-aggregated nanoparticles.

These experimental results suggest that human cells coated with PAH-MNPs undergo the following pathway (as shown in Figs. 7(a)): (1) Cells coated with aggregated MNPs attach to the substrate; (2) the attached cells spread on the substrate, which initiates the elongation of the cells and consequently promotes the dissociation of nanoparticle aggregates; and finally (3) cells actively divide, sharing MNPs between "mother" and "daughter" cells, gradually reducing the number of aggregates on the cellular membranes. We believe that the nanoparticles are gradually removed from the cell surfaces and are likely to be accumulated in the extracellular matrix; the fate of the MNPs will be the subject of a further study. Surface-functionalized cells effectively attach to and spread on substrates because the MNPs do not alter the functionalities of cell surface adhesion proteins. As demonstrated using high-resolution microscopy (Fig. 2) and zeta-potential measurements, MNPs attached to cell microvilli do not completely cover the 

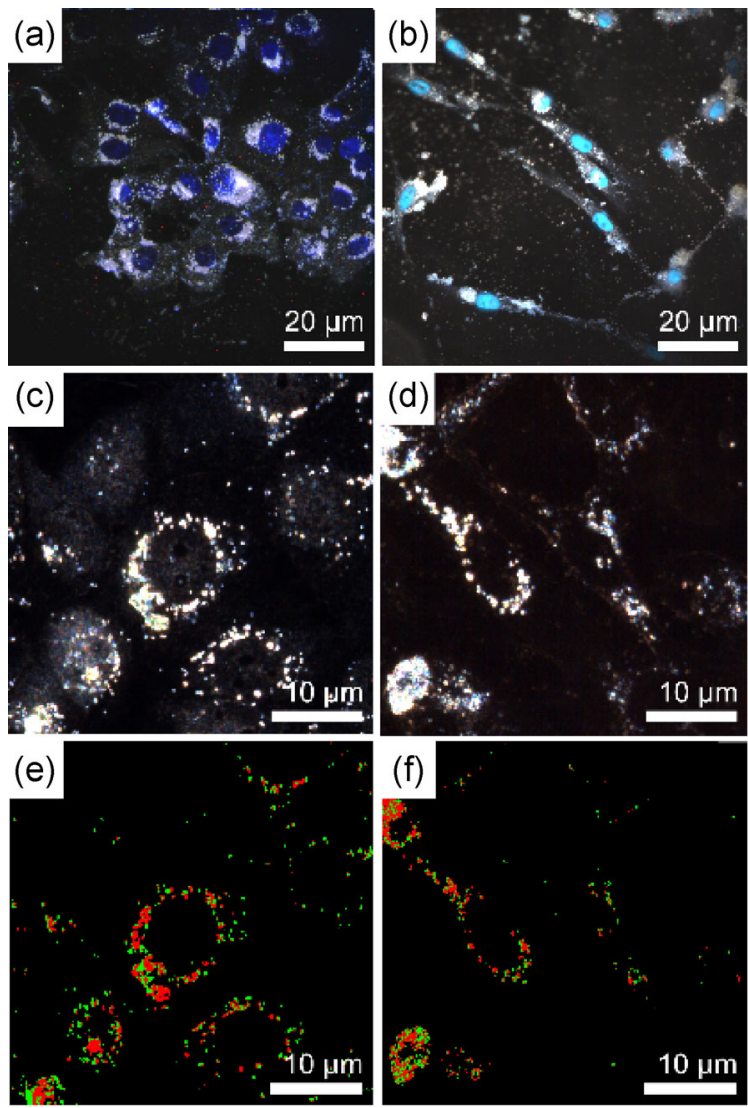

Figure 8 Merged fluorescent (DAPI-stained nuclei) and EDF (MNPs) microscopy images of magnetically functionalized A549 (a) and HSF (b) cells attached to the surface; hyperspectral images of MNPs distribution in A549 (c) and HSF (d) and respective hyperspectral mapping of MNPs ((e) and (f)), demonstrating the distribution of aggregated (red) and isolated (green) MNPs.

cell surface, as in microbial cells [21], but leave sufficient nanoparticle-free areas. The nanoparticle coating is labile and can easily be moved and displaced during cellular adhesion and division. High adhesion and proliferation rates for PAH-MNPs surface-functionalized human cells (A549 and HSF) were earlier demonstrated by our group, using real-time cell index monitoring [20]. The preservation of adhesion behavior in surfacemodified magnetic human cells makes our approach attractive for tissue engineering, especially if compared with intracellular magnetic labeling, which was reported to affect cell spreading and hence to reduce cell adhesive properties [34, 35]. Overall, the preserved viability and adhesive properties of MNPs-coated cells encouraged us to apply these cells for fabrication of two types of artificial tissue prototypes: layered and three-dimensional.

\subsection{Fabrication of layered planar tissue constructs and multicellular spheroids using MNPs-functionalized cells}

Current tissue engineering techniques based on intracellular magnetization of cells have extensively used magnetically labeled cells for fabrication of layered structures [3] or multicellular spheroids [36]. We employed magnetically functionalized A549 and HSF cells for fabrication of artificial lung-mimicking layered tissue-like constructs [20]. Magnetic cells were deposited layer-wise onto culture wells, starting with HSF $\left(0.3 \times 10^{6}\right.$ cells per well) and finishing with A549 cells $\left(0.5 \times 10^{6}\right.$ cells per well). The positioning of the MNPs-coated cells was facilitated by $3 \mathrm{~mm} \mathrm{NdFeB}$ cylindrical magnets positioned under the wells. Each layer of MNPs-coated cells was incubated for $24 \mathrm{~h}$, then the loosely attached cells were washed away. After removing the supporting magnets, the resulting multicellular clusters $(\sim 100 \mu \mathrm{m}$ thick, round, and $3 \mathrm{~mm}$ in diameter) were defoliated from the substrates and were imaged using optical bright light and dark-field microscopies. The twolayered architecture of HSF and A549 cells in the clusters is supported by the proliferating viable cells (Fig. 9(a)). Notably, the porous morphology of the artificial multicellular clusters mimics the morphology of normal human lung tissue [20]. Enhanced darkfield high-resolution microscopy (Fig. 9(b)) shows the brown aggregated MNPs between the tissue-forming cells. To investigate the exact distribution of MNPs, we employed hyperspectral mapping (Fig. 9(c)), which is based on reflected light spectra collected from the whole field of view, using a microscope-attached spectrometer. As a reference, we used the spectrum collected from the MNPs. We found that the MNPs in the multicellular clusters were concentrated predominantly in extracellular areas, which indicates that the MNPs are gradually removed from the proliferating cells.

Magnetic nanoparticles removed from the cells and accumulated in the extracellular matrix can be utilized in magnetically facilitated manipulation of the clusters, which allows for effective spatial control over the positioning of the clusters.

Finally, to demonstrate the applicability of PAHMNPs-based human cell surface modification for tissue 
engineering, we fabricated multicellular spheroids based on MNPs-coated A549 cells. Multicellular spheroids are cultivated as 3D-cell culture models employed in cancer research [37-39] and pharmaceutical screening [40,41]; in addition, applications of spheroids as building blocks in tissue engineering have been envisaged [36, 42-44]. Thus, rendering multicellular spheroids with magnetic functionality is deemed important for assembly of artificial tissues, and magnetic nanoparticles have been introduced into cells prior to fabrication of spheroids [9]. Importantly, PAH-stabilized MNPs are equally applicable to both primary and malignant cells, whereas earlier reports suggest different ways to functionalize cancer and normal cells [45, 46]. Magnetic functionality in spherical tissue engineering blocks is pivotal for the effective positioning and retention of spheroids at desired areas during tissue build-up. However, the intercellular labeling or introduction of magnetic nanoparticles into the internal volume of spheroids imposes certain limitations. Here, we utilized a cell surface engineering approach to induce magnetic responsiveness into the A549 cell-built multicellular spheroids. Spheroid formation followed microscopically during their growth, and the results are given in Fig. 10.

The magnetic behavior of MNPs-functionalized spheroids is demonstrated in Movie S1 in the Electronic Supplementary Material (ESM), in which the spheroids are manipulated by a permanent magnet. The morphology of spheroids grown in hanging drops using magnetically functionalized cells matched that of those fabricated using non-magnetic A549 cells (data not shown). We found that the growth rates of magnetic and non-magnetic spheroids were similar, suggesting that the PAH-stabilized MNPs do not impede the growth of cells in 3-D constructs. EDF microscopy images (Figs. 10(d) and 10(e)) demonstrate that the MNPs are diffusely distributed on the cell membranes and inside cells, which corresponds well with the results obtained using cells growing on planar substrates. The nuclei were counter-stained with DNA-targeting DAPI dye, suggesting that the MNPs do not penetrate the nuclei, thus reducing the risk of mutations. Notably, MNPs-functionalized spheroids could be collected from the hanging drops and then placed on cell growth substrates, where they eventually spread and colonized the substrate (Fig. 10(f); note the remaining MNPsfunctionalized cell at the center of the spheroid, whereas the proliferating cells bear no visible MNPs at the membranes).

The development of MNPs surface-engineered cellbased spheroids apparently follows the same pathway as the growth of pure spheroids; consequently, the fundamental biochemical processes are not disrupted by MNPs. We demonstrated previously that enzymatic activity in MNPs-coated cells is not affected; attachment and proliferation are actually stimulated by MNPs $[18,20]$. The cytoskeleton plays a pivotal role in major cellular processes, and therefore the building and functions of the cytoskeleton should not be jeopardized by the MNPs. Here, we applied confocal microscopy and phalloidin staining (conjugated with Alexa Fluor
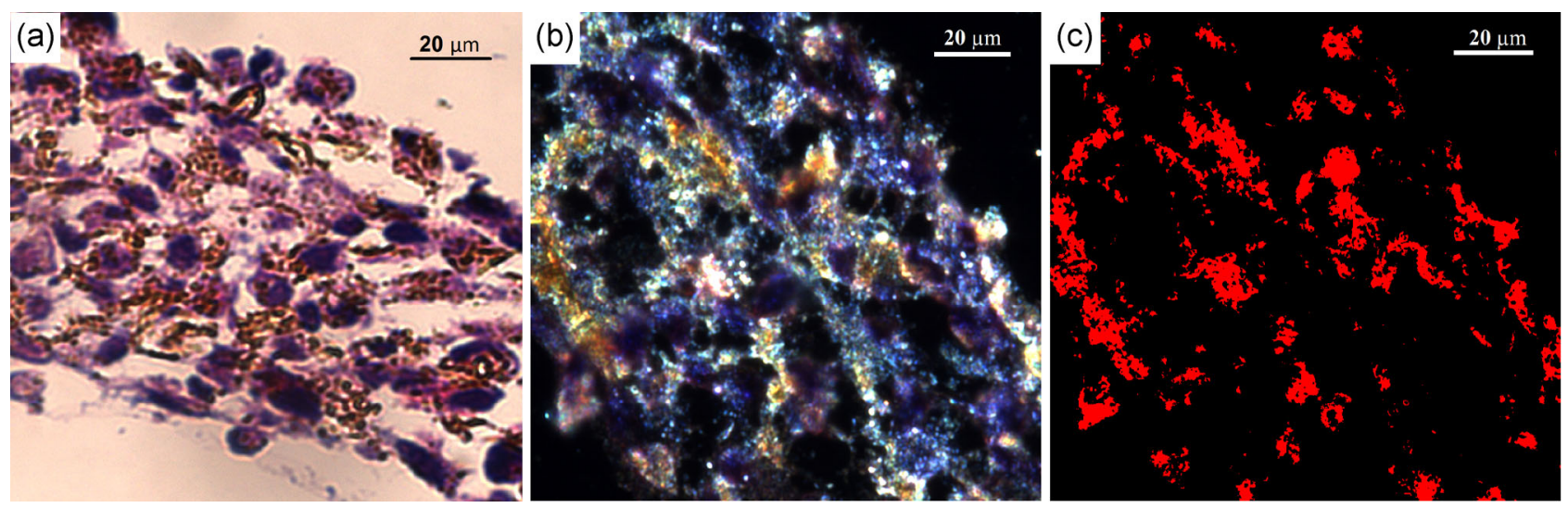

Figure 9 Optical microscopy image of thin sectioned hematoxylin-eosin stained magnetically facilitated multicellular cluster fabricated using MNPs-functionalized A 549 and HSF cells (a); hyperspectral microscopy image of the multicellular cluster (b); corresponding hyperspectral map (matching the image in (b)) illustrating the distribution of MNPs (red) in the extracellular areas (c).

TINIVERITY PRESS TS Springer | www.editorialmanager.com/nare/default.asp 

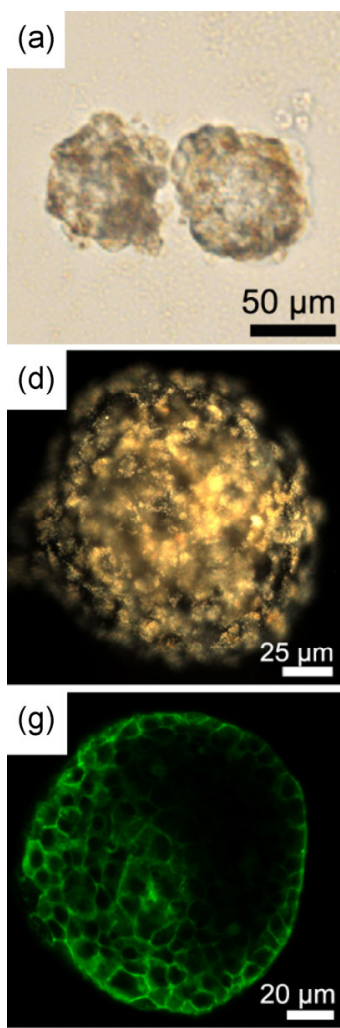

(b)
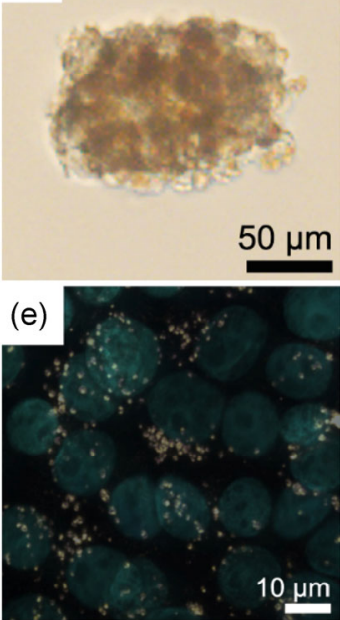

(h)

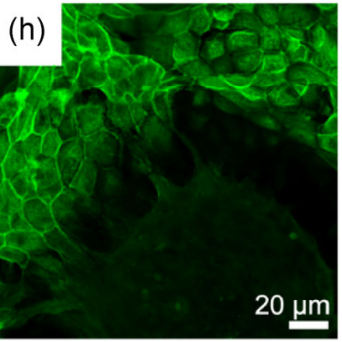

(c)
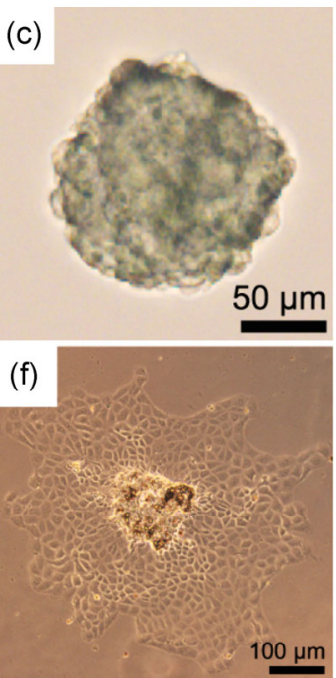

(i)

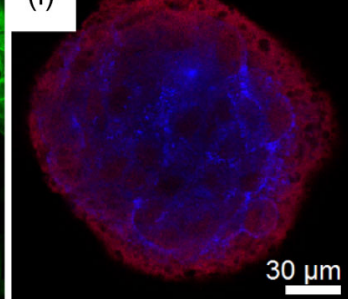

Figure 10 Generation of magnetic spheroids using MNPs-coated A 549 cells: 24-h (a), 48-h (b) and 7-d (c) spheroids grown in hanging drops; EDF image of 7-d spheroid demonstrating the diffused MNPs at the cellular membranes (d) and merged fluorescence (DAPI) and EDF image of MNPs inside cells (e); proliferation of spheroid cells after seeding onto an adhesion surface (note the MNPs remaining at the centre of the spheroid) (f); F-actin visualization of a magnetic spheroid (g) and proliferated adhesive cells (h) using phalloidin/Alexa Fluor 488 staining (note the differences in F-actin distribution in 3D and 2D cell assemblies); multicellular spheroid from A549 (blue) and HeLa (red) cells labelled with DID and Dil (i).

488 dye) to investigate the possible effects of $\mathrm{PAH}$ coated MNPs on the cytoskeleton of A549 cells. As shown in the confocal images, actin filaments in MNPscoated cells in the multicellular spheroids were not disrupted, indicating normal cytoskeleton formation in surface-engineered cells. These results explain the successful growth of spheroids transferred onto planar adhesive substrates, since cytoskeleton functions are crucial during attachment and colonization.

Finally, to further demonstrate the feasibility of our approach, we fabricated hybrid multicellular spheroids using two different types of cells: A549 and HeLa human cancer cell lines. We used HeLa cells instead of HSF cells because of their higher proliferation rate. The cells we co-cultured are similar to the single-culture spheroids. Prior to assembly, the cells were fluorescence-tagged to enable visualization using confocal microscopy. As shown in Fig. 10(i), A549 cells (blue) and HeLa cells (red) self-assembled into multicellular spherical structures, similar to single-culture spheroids.

\section{Conclusion}

We demonstrate here a new way to fabricate magnetically responsive viable human cells, employing cell surface engineering with polymer-stabilized magnetic nanoparticles. Cationic polyelectrolyte-coated MNPs readily and rapidly attached to negatively charged cellular membranes, producing a mesoporous magnetic film. We characterized the formation of the nanoparticle layer and its removal during cell growth using TEM, SEM, AFM, and enhanced dark-field imaging. We convincingly demonstrate here that PAH-stabilized MNPs are highly biocompatible and do not impair membrane integrity, enzymatic activity, adhesion, proliferation, or cytoskeleton formation, and do not 
induce apoptosis in either cancer or primary cells. Finally, magnetically functionalized cells were employed to fabricate viable magnetically responsive planar cell sheets and 3D multicellular spheroids. We believe that the approach described here will be a potent tool in tissue engineering and regenerative medicine.

\section{Acknowledgements}

We thank Mr. A. Badrutdinov, Dr. A. Ulianenkov (OPTEC) and Dr. A. Dulebo (Bruker) for AFM imaging and Dr. R. Dzamukov for histology samples and fruitful discussions. We also thank Ms A. Dubkova for technical help. The work is performed according to the Russian Government Program of Competitive Growth of Kazan Federal University. This work was funded by the subsidy allocated to Kazan Federal University for the state assignment in the sphere of scientific activities. This study was supported by RFBR 12-04-33290_mol_ ved_a grant and RFBR 15-04-99660 grant.

Electronic Supplementary Material: Supplementary material (Movie demonstrating the magnetic behavior of MNPs-functionalized multicellular spheroids) is available in the online version of this article at http://dx.doi.org/10.1007/s12274-015-0759-1.

\section{References}

[1] Ito, A.; Jitsunobu, H.; Kawabe, Y.; Kamihira, M. Construction of heterotypic cell sheets by magnetic force-based 3-D coculture of HepG2 and NIH3T3 cells. J. Biosci. Bioeng. 2007, 104, 371-378.

[2] Perea, H.; Aigner, J.; Heverhagen, J. T.; Hopfner, U.; Wintermantel, E. Vascular tissue engineering with magnetic nanoparticles: Seeing deeper. J. Tissue Eng. Regen. Med. 2007, 1, 318-321.

[3] Ito, A.; Takizawa, Y.; Honda, H.; Hata, K.; Kagami, H.; Ueda, M.; Kobayashi, T. Tissue engineering using magnetite nanoparticles and magnetic force: Heterotypic layers of cocultured hepatocytes and endothelial cells. Tissue Eng. 2004, 10, 833-840.

[4] Shimizu, K.; Ito, A.; Arinobe, M.; Murase, Y.; Iwata, Y.; Narita, Y.; Kagami, H.; Ueda, M.; Honda, H. Effective cellseeding technique using magnetite nanoparticles and magnetic force onto decellularized blood vessels for vascular tissue engineering. J. Biosci. Bioeng. 2007, 103, 472-480.

[5] Yamamoto, Y.; Ito, A.; Kato, M.; Kawabe, Y.; Shimizu, K.; Fujita, H.; Nagamori, E.; Kamihira, M. Preparation of artificial skeletal muscle tissues by a magnetic force-based tissue engineering technique. J. Biosci. Bioeng. 2009, 108, 538-543.

[6] Ito, A.; Takahashi, T.; Kawabe, Y.; Kamihira, M. Human beta defensin-3 engineered keratinocyte sheets constructed by a magnetic force-based tissue engineering technique. J. Biosci. Bioeng. 2009, 108, 244-247.

[7] Mattix, B.; Olsen, T. R.; Gu, Y.; Casco, M.; Herbst, A.; Simionescu, D. T.; Visconti, R.P.; Kornev, K. G.; Alexis, F. Biological magnetic cellular spheroids as building blocks for tissue engineering. Acta Biomater. 2014, 10, 623-629.

[8] Mattix, B. M.; Olsen, T. R.; Casco, M.; Reese, L.; Poole, J. T.; Zhang, J.; Visconti, R. P.; Simionescu, A.; Simionescu, D. T.; Alexis, F. Janus magnetic cellular spheroids for vascular tissue engineering. Biomaterials 2014, 35, 949-960.

[9] Ho, V. H. B.; Müller, K. H.; Barcza, A.; Chen, R. J.; Slater, N. K. H. Generation and manipulation of magnetic multicellular spheroids. Biomaterials 2010, 31, 3095-3102.

[10] Tseng, H.; Balaoing, L. R.; Grigoryan, B.; Raphael, R. M.; Killian, T. C.; Souza, G. R.; Grande-Allen, K. J. A threedimensional co-culture model of the aortic valve using magnetic levitation. Acta Biomater. 2014, 10, 173-182.

[11] Gloria, A.; Russo, T.; D’Amora, U.; Zeppetelli, S.; D’Alessandro, T.; Sandri, M.; Bañobre-López, M.; PiñeiroRedondo, Y.; Uhlarz, M.; Tampieri, A.; et al. Magnetic poly(e-caprolactone)/iron-doped hydroxyapatite nanocomposite substrates for advanced bone tissue engineering. J. R. Soc. Interface 2013, 10, 20120833.

[12] Andreas, K.; Georgieva, R.; Ladwig, M.; Mueller, S.; Notter, M.; Sittinger, M.; Ringe, J. Highly efficient magnetic stem cell labeling with citrate-coated superparamagnetic iron oxide nanoparticles for MRI tracking. Biomaterials 2012, 33, 4515-4525.

[13] Akiyama, H.; Ito, A.; Kawabe, Y.; Kamihira, M. Genetically engineered angiogenic cell sheets using magnetic force-based gene delivery and tissue fabrication techniques. Biomaterials 2010, 31, 1251-1259.

[14] Chaudeurge, A.; Wilhelm, C.; Chen-Tournoux, A.; Farahmand, P.; Bellamy, V.; Autret, G.; Ménager, C.; Hagège, A.; Larghéro, J.; Gazeau, F.; et al. Can magnetic targeting of magnetically labeled circulating cells optimize intramyocardial cell retention? Cell Transpl. 2012, 21, 679-691.

[15] Babič, M.; Horák, D.; Trchová, M.; Jendelová, P.; Glogarová, K.; Lesný, P.; Herynek, V.; Hájek, M.; Syková, E. Poly(L-lysine)-modified iron oxide nanoparticles for stem cell labeling. Bioconjugate Chem. 2008, 19, 740-750. 
[16] Tomitaka, A.; Koshi, T.; Hatsugai, S.; Yamada, T.; Takemura, Y. Magnetic characterization of surface-coated magnetic nanoparticles for biomedical application. J. Magn. Magn. Mater. 2011, 323, 1398-1403.

[17] Kim, J. A.; Choi, J. H.; Kim, M.; Rhee, W. J.; Son, B.; Jung, H. K.; Park, T. H. High-throughput generation of spheroids using magnetic nanoparticles for three-dimensional cell culture. Biomaterials 2013, 34, 8555-8563.

[18] Dzamukova, M. R.; Naumenko, E. A.; Zakirova, E. Y.; Dzamukov, R. A.; Shilyagin, P. A.; Ilinskaya, O. N.; Fakhrullin, R. F. Polymer-stabilised magnetic nanoparticles do not affect the viability of magnetically-functionalised cells. Cell. Transpl. Tissue Eng. 2012, 7, 52-56.

[19] Zhang, M. L.; Earhart, C.M.; Ooi, C.; Wilson, R.J.; Tang, M.; Wang, S. X. Functionalization of high-moment magnetic nanodisks for cell manipulation and separation. Nano Res. 2013, 6, 745-751.

[20] Dzamukova, M. R.; Naumenko, E. A.; Lannik, N. I.; Fakhrullin, R. F. Surface-modified magnetic human cells for scaffold-free tissue engineering. Biomater. Sci. 2013, 1, 810-813.

[21] Fakhrullin, R. F.; Paunov, V. N. Fabrication of living cellosomes of rod-like and rhombohedral morphologies based on magnetically responsive templates. Chem. Commun. 2009, 2511-2513.

[22] Zhang, D. Y.; Fakhrullin, R. F.; Özmen, M.; Wang, H.; Wang, J.; Paunov, V. N.; Li, G. H.; Huang, W. E. Functionalization of whole-cell bacterial reporters with magnetic nanoparticles. Microb. Biotechnol. 2011, 4, 89-97.

[23] Fakhrullin, R. F.; Shlykova, L.V.; Zamaleeva, A. I.; Nurgaliev, D. K.; Osin, Y. N.; García-Alonso, J.; Paunov, V. N. Interfacing living unicellular algae cells with biocompatible polyelectrolyte-stabilised magnetic nanoparticles. Macromol. Biosci. 2010, 10, 1257-1264.

[24] Fakhrullin, R. F.; García-Alonso, J.; Paunov, V. N. A direct technique for preparation of magnetically functionalised living yeast cells. Soft Matter 2010, 6, 391-397.

[25] Dzamukova, M. R.; Zamaleeva, A. I.; Ishmuchametova, D. G.; Osin, Y. N.; Kiyasov, A. P.; Nurgaliev, D. K.; Ilinskaya, O. N.; Fakhrullin R. F. A direct technique for magnetic functionalization of living human cells. Langmuir 2011, 27, 14386-14393.

[26] Wilhelm, C.; Gazeau, F. Universal cell labelling with anionic magnetic nanoparticles. Biomaterials 2008, 29, 3161-3174.

[27] Huang, C.-Y.; Ger, T.-R.; Wei, Z.-H.; Lai, M.-F. Compare analysis for the nanotoxicity effects of different amounts of endocytic iron oxide nanoparticles at single cell level. PLoS One 2014, 9, e96550.
[28] Liu, S-Y.; Long, L.; Yuan, Z.; Yin, L.-P.; Liu, R. Effect and intracellular uptake of pure magnetic $\mathrm{Fe}_{3} \mathrm{O}_{4}$ nanoparticles in the cells and organs of lung and liver. Chin. Med. J. 2009, 122, 1821-1825.

[29] Hoskins, C.; Wang, L. J.; Cheng, W. P.; Cuschieri, A. Dilemmas in the reliable estimation of the in-vitro cell viability in magnetic nanoparticle engineering: Which tests and what protocols? Nanoscale Res. Lett. 2012, 7, 77.

[30] Luther, E.; Petters, C.; Bulcke, F.; Kaltz, A.; Thiel, K.; Bickmeyer, U.; Dringen, R. Endocytotic uptake of iron oxide nanoparticles by cultured brain microglial cells. Acta Biomater. 2013, 9, 8454-8465.

[31] Griffon, G.; Marchal, C.; Merlin, J. L.; Marchal, S.; Parache, R. M.; Bey, P. Radiosensitivity of multicellular tumour spheroids obtained from human ovarian cancers. Eur. J. Cancer 1995, 31, 85-91.

[32] Couchman, J. R.; Höök, M.; Rees, D. A.; Timpl, R. Adhesion, growth, and matrix production by fibroblasts on laminin substrates. J. Cell Biol. 1983, 96, 177-183.

[33] Konnova, S. A.; Sharipova, I. R.; Demina, T.; Osin, Y. N.; Yarullina, D. R.; Ilinskaya, O. N.; Lvov, Y. M.; Fakhrullin, R. F. Biomimetic cell-mediated three-dimensional assembly of halloysite nanotubes. Chem. Commun. 2013, 49, 42084210 .

[34] Soenen, S. J.; Himmelreich, U.; Nuytten, N.; Pisanic, T. R.; Ferrari, A.; De Cuyper, M. Intracellular nanoparticle coating stability determines nanoparticle diagnostics efficacy and cell functionality. Small 2010, 6, 2136-2145.

[35] Buyukhatipoglu, K.; Clyne, A. M. Superparamagnetic iron oxide nanoparticles change endothelial cell morphology and mechanics via reactive oxygen species formation. J. Biomed. Mater. Res. 2011, 96A, 186-195.

[36] Yoon, S.; Kim, J. A.; Lee, S. H.; Kim, M.; Park, T. H. Droplet-based microfluidic system to form and separate multicellular spheroids using magnetic nanoparticles. $L a b$ Chip 2013, 13, 1522-1528.

[37] Lin, R.-Z.; Chu, W.-C.; Chiang, C.-C.; Lai, C.-H.; Chang, H.-Y. Magnetic reconstruction of three-dimensional tissues from multicellular spheroids. Tissue Eng. 2008, 14, 197-205.

[38] Walser, R.; Metzger, W.; Görg, A.; Pohlemann, T.; Menger, M. D.; Laschke, M. W. Generation of co-culture spheroids as vascularisation units for bone tissue engineering. Eur. Cells Mater. 2013, 26, 222-233.

[39] Carver, K.; Ming, X.; Juliano, R. L. Multicellular tumor spheroids as a model for assessing delivery of oligonucleotides in three dimensions. Mol. Ther. Nucleic Acids 2014, 3, e153.

[40] Dufau, I.; Frongia, C.; Sicard, F.; Dedieu, L.; Cordelier, P.; Ausseil, F.; Ducommun, B.; Valette, A. Multicellular tumor 
spheroid model to evaluate spatio-temporal dynamics effect of chemotherapeutics: Application to the gemcitabine/CHK1 inhibitor combination in pancreatic cancer. BMC Cancer 2012, 12, 15-26.

[41] Kunz-Schughart, L. A.; Kreutz, M.; Knuechel, R. Multicellular spheroids: A three-dimensional in vitro culture system to study tumour biology. Int. J. Exp. Pathol. 1998, 79, 1-23.

[42] Xia, L.; Sakban, R. B.; Qu, Y. H.; Hong, X.; Zhang, W. X.; Nugraha, B.; Tong, W. H.; Ananthanarayanan, A.; Zheng, B.; Chau, I. Y.-Y.; et al. Tethered spheroids as an in vitro hepatocyte model for drug safety screening. Biomaterials 2012, 33, 2165-2176.

[43] Breslin, S.; O’Driscoll L. Three-dimensional cell culture: The missing link in drug discovery. Drug Discov. Today 2013, 18 , 240-249.

[44] Chan, H. F.; Zhang, Y.; Ho, Y.-P.; Chiu, Y.-L.; Jung, Y.; Leong, K. W. Rapid formation of multicellular spheroids in double-emulsion droplets with controllable microenvironment. Sci. Rep. 2013, 3, 3462.

[45] Mahmoudi, M.; Simchi, A.; Milani, A. S.; Stroeve, P. Cell toxicity of superparamagnetic iron oxide nanoparticles. $J$. Colloid Interface Sci. 2009, 336, 510-518.

[46] Berry, C. C.; Wells, S.; Charles, S.; Curtis, A. S. G. Dextran and albumin derivatised iron oxide nanoparticles: Influence on fibroblasts in vitro. Biomaterials 2003, 24, 4551-4557. 